\title{
Somatostatin analogs therapy in gastroenteropancreatic neuroendocrine tumors: current aspects and new perspectives
}

\section{Roberto Baldelli ${ }^{1}$, A. Barnabei ${ }^{1}$, L. Rizza ${ }^{2}$, A. M. Isidori ${ }^{2}$, F. Rota ${ }^{1}$, P. Di Giacinto ${ }^{3}$, A. Paoloni ${ }^{1}$, F. Torino ${ }^{4}$, S. M. Corsello ${ }^{5}, A$. Lenzi $^{2}$ and M. Appetecchia ${ }^{1}$}

\author{
Endocrinology Unit, Regina Elena National Cancer Institute, Rome, Italy \\ 2 Section of Endocrinology, Department of Experimental Medicine, "Sapienza" University of Rome, Rome, Italy \\ ${ }^{3}$ Section of Reproductive Endocrinology, Department of Systems Medicine, Tor Vergata University of Rome, Fatebenefratelli Hospital, Rome, Italy \\ ${ }^{4}$ Department of Systems Medicine, Tor Vergata University of Rome, Rome, Italy \\ ${ }^{5}$ Department of Endocrinology, Catholic University of the Sacred Heart, Rome, Italy
}

\section{Edited by:}

Diego Ferone, University of Genova,

Italy

\section{Reviewed by:}

Daniela Pasquali, Seconda Università degli Studi Napoli, Italy

Michele Milella, Regina Elena

National Cancer Institute, Italy

Antongiulio Faggiano, Federico II

University of Naples, Italy

*Correspondence:

Roberto Baldelli, Endocrinology Unit, Regina Elena National Cancer

Institute, via Elio Chianesi, 53, Rome,

00144 Italy

e-mail: baldelli@ifo.it
Gastroenteropancreatic neuroendocrine tumors (GEP-NETs) are rare tumors that present many clinical features secreting peptides and neuroamines that cause distinct clinical syndromes such as carcinoid syndrome. However most of them are clinically silent until late presentation with mass effects. Surgical resection is the first line treatment for a patient with a GEP-NET while in metastatic disease multiple therapeutic approaches are possible. GEP-NETs are able to express somatostatin receptors (SSTRs) bounded by somatostatin (SST) or its synthetic analogs, although the subtypes and number of SSTRs expressed are very variable. In particular, SST analogs are used frequently to control hormone-related symptoms while their anti-neoplastic activity seems to result prevalently in tumor stabilization. Patients who fail to respond or cease to respond to standard SST analogs treatment seem to have a response to higher doses of these drugs. For this reason, the use of higher doses of SST analogs will probably improve the clinical management of these patients.

Keywords: neuroendocrine tumors, somatostatin analogs, lanreotide, octreotide, carcinoid

\section{INTRODUCTION}

Gastroenteropancreatic neuroendocrine tumors (GEP-NETs) are characterized by an yearly incidence of $1.2-3.0$ cases $/ 100,000$ inhabitants (1-5). The majority of the GEP-NETs are sporadic but they can be also part of familiar syndromes such as MEN 1 syndrome, von Hippel-Lindau disease, and neurofibromatosis type 1 while the clinical characteristics depend on the site of the primary tumor and its ability to secrete neuroamines and peptides. Among functioning tumors, major clinical entities are represented by carcinoid syndrome, hypoglycemic syndrome, Zollinger-Ellison syndrome, WDHA (Water Diarrhea-Hypokalemia-Achlorydria) syndrome, and glucagonoma syndrome. However most of the GEP-NETs are not able to produce biologically active hormones (non-functioning tumors) and therefore the diagnosis is often made too late only for the presence of symptoms due to the mass effect and/or metastases, mainly hepatic (1). In patients with localized well-differentiated neuroendocrine carcinomas, 5-yearsurvival is $60-100 \%$ while with regional disease or distant metastases 5-year-survival is 40 and $29 \%$, respectively (6). Around $80 \%$ of GEP-NETs express somatostatin receptors (SSTRs); they are five different G-protein coupled receptor subtypes (SSTRs 1-5) that are differently expressed in the various types of tumor (Tables 1 and 2). It is important to underline that SSTRs are present not only in neoplastic tissues. For example Beneyto and co-workers used in situ hybridization to quantify the mRNA expression levels of SST receptors subtype 1 (SSTR1) and subtype 2 (SSTR2) in dorsolateral prefrontal cortex area 9 from 23 matched pairs of subjects with schizophrenia and normal comparison subjects. SSTR1 mRNA levels did not differ between subject groups while mean cortical SSTR2 mRNA levels were significantly 19\% lower in the subjects with schizophrenia (7). Moreover in a very interesting and complete work, Pasquali and co-workers, reported that the radiolabeled somatostatin (SST) analog octreotide accumulates within the orbits of active Graves' ophthalmopathy (GO), and octreotide and lanreotide have been proposed to treat this disorder. In particular, the authors described the expression of SST1-5 genes in lymphocytes recovered from retroorbital tissues obtained from patients with GO undergoing orbital decompression. All SSTs transcripts were found in lymphocytes both from GO retroorbital tissues and blood samples (8). In addition, recent studies have shown that SSTRs are preferably expressed in welldifferentiated neoplasia and some advanced forms loose particular receptor subtypes while keeping others $(9,10)$; SSTRs subtypes can form homo/heterodimers at the membrane level, developing new receptors with different functional features (11), and that this receptor dimerization may be induced by addition of either dopamine or SST (Figure 1). In a study examining 81 functioning and non-functioning GEP-NETs the large part of the tumors expressed SSTRs 1, 2, 3, and 5, while SSTR 4 was detected only in a small minority (12). SSTRs have been extensively mapped in different pancreatic tumors by means of autoradiography, reversetranscription polymerase chain reaction, in situ hybridization, and immunohistochemistry; SSTRs 1, 2, 3, and 5 are usually expressed in pancreatic NETS in particular insulinomas had heterogeneous 
Table 1 | Somatostatin receptors ${ }^{a}$ in neuroendocrine gastroenteropancreatic tumors (\%).

\begin{tabular}{lccccc}
\hline & SSTR1 & SSTR2 & SSTR3 & SSTR4 & SSTR5 \\
\hline All & 68 & 86 & 46 & 93 & 57 \\
Insulinoma & 33 & $100^{\mathrm{b}}$ & 33 & 100 & 67 \\
Gastrinoma & 33 & 50 & 17 & 83 & 50 \\
Glucagonoma & 67 & 100 & 67 & 67 & 67 \\
VIPoma & 100 & 100 & 100 & 100 & 100 \\
N-F & 80 & 100 & 40 & 100 & 60 \\
\hline
\end{tabular}

IP, vasoactive intestinal polypeptide; $N-F$, non-functioning.

${ }^{a}$ Using receptor subtype antibodies.

${ }^{b}$ Malignant insulinoma.

Modified from Oberg et al. (15).

SSTRs expression while $100 \%$ of somatostatinomas expressed SSTR 5 and $100 \%$ of gastrinomas and glucagonomas expressed SSTR 2 (13). SST is a natural peptide hormone secreted in various parts of the human body, including the digestive tract, able to inhibit the release of numerous endocrine hormones, including insulin, glucagon, and gastrin. The biological effects of SST are mediated through its specific receptors (SSTRs 1-5) all bind natural peptides (SST-14, SST-28, and cortistatin) with similar high affinity. However, endogenous SST short half-life in circulation (1$3 \mathrm{~min}$ ), makes it difficult to use it continuously and has resulted in the development of synthetic analogs from the early 1980s when a number of short synthetic analogs of SST including SMS201995 (octreotide), RC-160 (vapreotide), BIM 23014 (lanreotide), and MK 678 (seglitide) were developed. These cyclic octapeptides are more resistant to peptidases and their half-lives and hence their biological activities are substantially longer than native SST (1.5-2 h vs. 1-2 min) (14). Moreover the development of a depot formulation of octreotide [octreotide long-acting repeatable (LAR) ], administered up to $30 \mathrm{mg}$ once every 4 weeks has to a large extent eliminated the need for daily injections. Lanreotide SR (slow release) 30, 60, and $90 \mathrm{mg}$ formulations administered every 10-14 days, has a similar efficacy to octreotide in the treatment of carcinoid tumors (15). A new slow release depot preparation of lanreotide, lanreotide autogel, is administered subcutaneously up to $120 \mathrm{mg}$ once a month (16). Native SST and its synthetic analogs show different affinity for the five specific SSTRs (11, 12, 17). Native SST binds all the five receptor subtypes (SSTRs 1-5). The effects of the SST analogs are mediated by the interaction with SSTR 2 and 5 receptors while the new SST analog, pasireotide (SOM 230), shows higher binding capacity toward SSTRs 1, 2, 3, and 5 with no agonist activity at the type 4 receptor (17) (Table 3 ). Moreover, in vitro studies demonstrated that SOM 230 was more effective than octreotide to control cell proliferation and apoptosis (18). The different receptor subtypes binding affinities seems to result in different biological and clinical activities (12).

\section{THE SYMPTOMATIC AND BIOCHEMICAL EFFECTS OF SST ANALOGS}

Gastroenteropancreatic neuroendocrine tumors first line therapy, where possible, is always an aggressive surgical approach, aimed to obtain a curative tumor ablation, even in the presence
Table 2 | Somatostatin receptor subtypes mRNA in neuroendocrine tumors.

\begin{tabular}{lccccc}
\hline Tumor & $\begin{array}{l}\text { SST1 } \\
\text { (\%) }\end{array}$ & $\begin{array}{l}\text { SST2 } \\
\text { (\%) }\end{array}$ & $\begin{array}{l}\text { SST3 } \\
\text { (\%) }\end{array}$ & $\begin{array}{l}\text { SST4 } \\
\text { (\%) }\end{array}$ & $\begin{array}{l}\text { SST5 } \\
(\%)\end{array}$ \\
\hline Gastrinoma & $79^{\mathrm{a}}$ & 93 & 36 & 61 & 93 \\
Insulinoma & 76 & 81 & 38 & 58 & 57 \\
Non-functioning pancreatic tumor & 58 & 88 & 42 & 48 & 50 \\
Carcinoid tumor of the gut & 76 & 80 & 43 & 68 & 77 \\
\hline
\end{tabular}

SST, somatostatin receptor.

andicates the percentage of positive tumors for each SSTRS MRNA expression may overestimate the number of receptors present, depending on the technique used (PR-polymerase chain reaction, Northern blot, in situ hybridization). Modified from Plockinger (19).

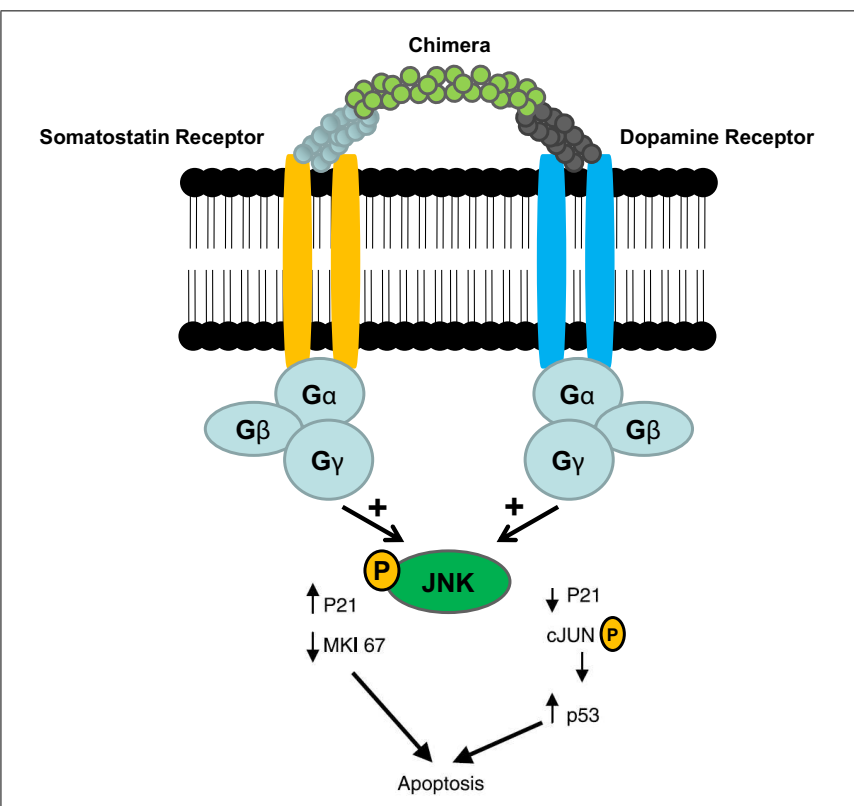

FIGURE 1 | Somatostatin/dopamine chimera-induced dimerization of somatostatin and dopamine receptors [Adapted from Ref. (11)]

of metastatic disease. However, in patients with functioning or metastatic tumors, the treatment goal is to improve their quality of life trying to alleviate the tumor associated symptoms and increasing survival $(2,14,15)$. Recently, the diagnostic and therapeutic approach of GEP-NETs has considerably improved, mainly due to better imaging techniques (CT, MRI, PET) and SST analog-based imaging methods, as well as receptor subtype characterization and the introduction of long-acting SST analogs (21-27). Usually, the treatment with long-acting preparations of SST analogs consists in an intramuscular injection (i.m.) every 2 or 4 weeks (octreotide-LAR, 10-30 mg; lanreotide autogel 60-120 mg) and the efficacy in the control of symptoms is well-documented $(2,14$, $15)$, even if patients with islet cell tumor often show a transient (median time 2.5 months) and non-significant response (21-27). The drugs are safe and well-tolerated in both long- and short-term treatments (28-32). However, after 9-12 months, drug resistance 
Table 3 | Somatostatin receptor subtype-binding affinity of somatostatin analogs.

\begin{tabular}{lccccc}
\hline Compound & SSTR1 & SSTR2 & SSTR3 & SSTR4 & SSTR5 \\
\hline RECEPTOR SUBTYPE AFFINITY & (IC50, nM) & & \\
Somatostatin-14 & 2.26 & 0.23 & 1.43 & 1.77 & 0.88 \\
Somatostatin-28 & 1.85 & 0.31 & 1.3 & ND & 0.4 \\
Octreotide & 1140 & 0.56 & 34 & 7030 & 7 \\
Lanreotide & 2330 & 0.75 & 107 & 2100 & 5.2 \\
Pasireotide & 9.3 & 1 & 1.5 & $>100$ & 0.16 \\
\hline
\end{tabular}

ND, not determined.

Modified from Ref. (20).

should appear and patients may show the symptoms of recrudescence. In such cases the approach proposed was to continue the treatment by increasing the analog dosage or by shortening the administration range (33). A randomized double-blind trial compared long-acting octreotide-LAR at 10, 20, and $30 \mathrm{mg}$ every 4 weeks with open-label short-acting octreotide every $8 \mathrm{~h}$ for the treatment of carcinoid syndrome. It showed that the efficacy of short-acting octreotide and of the long-acting octreotide-LAR was the same once circulating octreotide steady-state concentrations were achieved (34). O'Toole et al. in a multicentre study on 33 patients with the carcinoid syndrome comparing the treatment with lanreotide ( $30 \mathrm{mg}$ i.m. every 10 days) vs. octreotide ( $200 \mu$ g s.c. twice or thrice daily) founded no significant differences in controlling symptoms (53.8 and 45.4\%, respectively). Lanreotide and octreotide may also significantly lower the levels of the catabolite of serotonin (urinary 5-hydroxyindoleacetic acid/5-HIAA) (35). Ruszniewski et al. evaluated the efficacy and safety of the 28-day-aqueous prolonged release formulation of lanreotide in 75 patients in a 6-month-dose titration study where $30 \%$ of patients showed a biochemical response and 75 and $80 \%$ of patients reported resolution of diarrhea and flushing, respectively. The median decrease in levels of urinary 5-HIAA and serum chromogranin A was 24 and 38\%, respectively (36). An interim analysis of a phase II trial of SOM230 in 21 patients with metastatic carcinoid tumors whose symptoms (diarrhea and flushing) were refractory/resistant to octreotide-LAR showed symptom relief in $33 \%$ (37). Approximately $10-15 \%$ of patients with midgut carcinoids suffer from watery diarrhea, flushing, right-sided heart failure, and bronchial constriction (carcinoid syndrome), due to the tumor hypersecretion of a variety of endocrine substances, the most frequent of which are serotonin (5-hydroxytryptamine) and the tachykinins $(38,39)$, and therefore SST analogs are important palliative tools for these patients. In insulinoma it has been noted that octreotide treatment may induce hypoglycemia worse in those patients lacking SSTRs 2 and 5, and as glucagon secretion is also inhibited, patients have to be observed closely at the beginning of therapy to prevent severe hypoglycemia due to the reduced glucagon-dependent counter-regulation (19). Hence, this treatment has to be started in a hospital setting, and should be reserved only for the minority of insulinoma patients with positive imaging on SRS. Vezzosi et al. recently assessed that octreotide was effective in the control of hypoglycemia in more than $50 \%$ of the insulinoma patients (40). The treatment was effective in all SSTR 2 positive patients and in a few SSTR 2 negative ones, while no relation between treatment effectiveness and the expression of SSTR 5 was observed (40). These results are in concordance with other case reports and smaller series of insulinoma patients reported in the literature (41-45). In glucagonoma patients SST analog treatment is indicated to reduce the symptoms related to the characteristic skin rash (necrolytic migratory erythema) or diarrhea (46-50). Somatostatinomas symptoms are due to SST hypersecretion (hyperglycemia, cholelithiasis, diarrhea and steatorrhea, and hypochlorhydria) or to the mass effect (51). Although it seems a paradox to treat patients with symptoms related to elevated SST levels with a somatostatinoma, in 1998 Angeletti et al. showed that octreotide treatment was effective in reducing SST plasma levels and improving the related symptoms in three patients with metastatic somatostatinomas (52). Furthermore, nine cases of VIPoma have been described in which octreotide was very successful as adjuvant therapy for symptoms control and for reducing the serum elevated VIP levels by improving the diarrhea and the electrolyte imbalance (53-55).

\section{THE ANTI TUMOR EFFECTS OF SST ANALOGS}

The anti-neoplastic activity of SST analogs has been demonstrated in several experimental models in vivo and in vitro (56-61) but it is still little known regarding the anti-proliferative role of SSA in GEP-NETs, although increasing data suggest that such analogs can be tumoristatic, at least in some circumstances (62). The antineoplastic action of SST analogs depends on the kind of tumor and the receptor subtypes to which they are bound to and occurs through direct and indirect mechanisms. While direct activities are mediated by specific membrane receptors and include antimytotic and apoptotic effects, indirect effects do not depend on the receptor binding but depend on the growth factor inhibition, antiangiogenic, and immuno-modulating activities. SST analogs are able to inhibit the growth of Swarm chondrosarcoma, used as experimental model of SSTR free tumor (63). The mitosis inhibition is mediated by SSTRs 2 and 5 and results in the cell cycle arrest (56). The loss of the SSTR 2 expression in some human adenocarcinomas seems to be responsible for loosing the regulation of cell proliferation (10-19, 21-64). The loss of SSTR 2 may consequently promote tumor growth and make it clear the therapeutic inefficacy of SST analogs in such kind of neoplasia. Apoptosis seems to be induced by two different processes: interaction with the SSTR 3 (57) and inhibition of the Insulin-like Growth Factor I (IGF I), known as a potent antiapoptotic hormone (65). The pro-apoptotic activity of SST analogs seems to have clinical relevance, as shown by the interesting findings published by Eriksson et al. that reported an increase in apoptosis in bioptic samples of tissues by patients with GEP-NETs after the treatment with SST analogs at high doses. It followed that apoptosis is related to the biochemical response and the disease stabilization $(70 \%$ of cases) $(66,67)$. However, Faiss et al. observed an overall response rate (ORR) of $6.7 \%$, comparable to that recorded at conventional doses (68), in 24 patients with GEP-NETs treated with high doses of lanreotide ( $15 \mathrm{mg} /$ day). The indirect anti-proliferative efficacy of SST analogs is shown by an antiangiogenic mechanism. Tumor angiogenesis is essential in the development and metastatic spread 
of tumors, so the growth can be actually controlled by reducing the vascularization of the neoplastic tissue. In experimental models, octreotide shows a strong antiangiogenic effect, which is probably mediated by the inhibition of the Vascular Endothelial Growth Factor (VEGF) (69-71). The treatment with octreotide would result in a significant reduction in VEGF levels compared to the baseline, since it is related to the survival of the patients (71). It was observed that endothelial cells do not express the SSTR 2 that is present on the contrary, when they proliferate in order to form blood vessels. This could represent further opportunity to treat patients with octreotide that is able to recognize and inhibit new vessel formation both alone and with other drugs, thanks to its high affinity with such receptor (Table 3). Immunomodulation is another indirect mechanism of action of SST analogs. Preliminary evidence suggests that they stimulate the production of immune system components with antitumor effect, such as natural killer cells $(72,73)$, even if up to now it is not clear whether this can be clinically significant thus helping the antitumor efficacy of SST analogs. Few data exist on the functions mediated by the SSTR 4 . However, no unanimity exists about the SST analog ability to control (i.e., to slow) the tumor progression. In vitro studies reported that the response of different cell lines to the octreotide exposition produces a biphasic dose-response curve $(74,75)$. Consequently, overdose or underdose of SST analogs may result in a suboptimal anti-neoplastic activity. Nevertheless, the negative results of some clinical studies in terms of tumor response could be due to the administration of too low doses to achieve receptor optimal saturation. After all, in other studies that used octreotide doses higher than $8 \mathrm{mg} /$ day and lanreotide doses higher than $10 \mathrm{mg} /$ day (76), no improvement of the SST analog antitumor effect was observed. No study on the tumor response monitored plasma levels of an SST analog up to now, in order to assess that optimal drug therapeutic levels are reached but not exceeded (77). Tumor shrinkage was demonstrated in $<10 \%$ of the patients. However, a stabilization of tumor growth occurs in up to $50 \%$ of the patients with neuroendocrine tumors of various locations. Stable disease was observed in $37-45 \%$ of the patients with documented tumor progression before SSA therapy (Table 4). The median duration of stabilization was 26.5 months $(31,78-81)$. In a study on a selected group of patients with progressive disease, in the $47 \%$ of cases was demonstrated a stable disease when treated with a high dose of lanreotide (3-5 g/day) (82). This result has been confirmed in patients with advanced midgut carcinoids, who had a stabilization of the disease for 6-24 months in the $75 \%$ of cases (83). One patient with a pancreatic primary tumor and distant extrahepatic metastases, showed a poor response to treatment in multivariate analysis. Age, size of the primary tumor, and Ki67 did not influence the response rate to SSA therapy (81). A stabilization of the disease was maintain throughout long-term follow-up in patients who achieve it after 6 months of treatment; these patients live longer than those unresponsive to therapy $(81,84)$. Very recently, Rinke et al performed for the first time a placebo-controlled, doubleblind, and phase III B study in 85 patients with well-differentiated metastatic midgut NETs using octreotide-LAR $30 \mathrm{mg}$ intramuscularly in monthly intervals (PROMID study). Median time to tumor progression in the octreotide-LAR and placebo groups was 14.3 and 6 months, respectively. After 6 months of treatment, stable disease was observed in $66.7 \%$ of patients in the octreotide-LAR group and $37.2 \%$ of patients in the placebo group. Functionally active and inactive tumors responded similarly. The most favorable effect was observed in patients with low hepatic tumor load and resected primary tumor. Octreotide-LAR significantly lengthened the time to tumor progression compared with placebo in patients with functionally active and inactive metastatic midgut NETs (85). Midgut carcinoids express SSTRs in $80-100 \%$ of cases and SSTR 2 is the most frequently expressed (39). The anti-proliferative effect of SST analogs on the growth of the midgut carcinoids is unknown. A partial or complete responses were observed in $<10 \%$ of the patients, while stabilization of tumor growth was noticed in $24-57 \%$ of the patients (6). Few data are available regarding the role of SST analogs in the treatment of gastrinomas. In a study of 15 malignant gastrinoma, in about $50 \%$ of these patients, octreotide had an anti-proliferative effect, including one patient with tumor regression and seven patients with tumor stabilization (mean period 25 months) patients (86). The long-acting SST analog octreotide-LAR was administered in a patient with multiple type A gastric carcinoids for a period of 9 months with a normalization of serum gastrin levels and permanent disappearance of the tumor (87). Fykse et al. treated five patients with hypergastrinemia and gastric carcinoids for a period

Table 4 | Anti-proliferative effect of somatostatin analogues in patients with progressive disease.

\begin{tabular}{|c|c|c|c|c|c|c|c|}
\hline SSA & Dosagen & $n$ & CR & PR & SD & PD & Reference \\
\hline Lanreotide & $3000 \mu \mathrm{g} /$ day & 22 & 0 & 1 & 7 & 14 & (93) \\
\hline Lanreotide & 30 mg/2 weeks & 35 & 0 & 1 & 20 & 14 & $(91)$ \\
\hline Octreotide & $600 / 1500 \mu \mathrm{g} /$ day & 52 & 0 & 0 & 19 & 33 & $(75)$ \\
\hline Octreotide & $1500 / 3000 \mu \mathrm{g} /$ day & 58 & 0 & 2 & 27 & 29 & $(28)$ \\
\hline Lanreotide & $15000 \mu \mathrm{g} /$ day & 24 & 1 & 1 & 11 & 11 & (93) \\
\hline Octreotide & $600 \mu \mathrm{g} /$ day & 10 & 0 & 0 & 5 & 5 & $(74)$ \\
\hline \multicolumn{2}{|c|}{ Octreotide median dose of $250 \mu \mathrm{g}$ three times daily } & 34 & 0 & 1 & 17 & 0 & $(76)$ \\
\hline \multicolumn{2}{|c|}{ Octreotide-LAR 30/lanreotide SR 60 mg/28 days } & 31 & 0 & 0 & 14 & 4 & $(77)$ \\
\hline \multicolumn{2}{|c|}{ Total } & 256 & 1 & 6 & 115 & 105 & \\
\hline \multicolumn{2}{|c|}{ Percentage (\%) } & & 0.3 & 2 & 45 & 41 & \\
\hline
\end{tabular}

CR, complete remission; $P R$, partial remission; $S D$, stable disease; $P D$, progressive disease. 
of 1 year with monthly injections of octreotide-LAR with a significant reduction in tumor load, entero-chromaffin-like cells (ECL) cell density, and normalization of circulating chromogranin A levels, indicating a possible direct anti-proliferative effect of the treatment (88). These results suggest that the SST analogs could have an important anti-proliferative effect. However, data on the effect of SST analogs on tumor growth in patients with gastric carcinoids type $\mathrm{C}$ or poorly differentiated endocrine carcinomas are scanty. In poorly differentiated gastric carcinomas, treatment with SST analogs is not considered. As surgical excision is the definitive treatment of insulinoma, there are few contrasting data in the literature regarding the inhibitory effect of the SST analogs on the growth of these tumors. Grozinsky-Glasberg et al. have conducted a study regarding the effects of SST analogs on cell proliferation in the rat-derived insulinoma cell line (INS1). Their preliminary data show that octreotide has a significant inhibitory effect on cell proliferation, as assessed by cell counting and MTS assay, and on phosphorylation states of a number of proteins in the PI3K/Akt/mTOR pathway $(89,90)$. In his work, Vezzosi founded that despite achieving hypoglycemic control, insulinoma size remained unchanged or increased moderately despite normal blood glucose levels, concluding that SST analogs, as medical treatment is not sufficient to prevent tumor growth in patients with malignant insulinomas (40). In 2006, Romeo et al. reported a complete clinical remission with regression of the metastatic lesions in the liver after 1 year in a patient affected by metastatic insulinoma with severe hypoglycemia treated with octreotide-LAR (90). A more controversial area concerns the treatment of patients with non-functioning endocrine tumors of the pancreas as few studies have been published in these patients. The prospective German Sandostatin multicentre phase II trial investigated the effects of octreotide for 1 year on tumor growth in 103 patients and included 15 patients with diagnosed non-functional pancreatic tumors (79). Only 3 out of these 15 patients had a stable disease, in 8 patients a tumor progression occurred while the outcome of the remaining 4 patients was not clear. As previously reported, the SST analog efficacy depends on the tumor receptor expression patterns, but these are rarely assessed, even if there is evidence of better results on survival obtained with selective treatments. An anti-proliferative effect was achieved on hepatic metastatic cells in a patient with a carcinoid tumor, selected for the treatment with SST analogs after the immunohistochemical identification of the SSTRs 1,2, and 5 subtypes expression on the neoplastic cell surface (91). A complete clinical remission with regression of the metastatic lesions in the liver after 1 year of treatment was observed in a patient affected by metastatic insulinoma with severe hypoglycemia treated with octreotide-LAR expressing at immunohistochemical analysis of tissue specimens a strong membrane immunoreactivity for SSTR 2 in both the primary nodule and the metastases (90). However, another study showed neither an anti-neoplastic effect nor an increase in survival percentage of treated patients (92). It has been reported that in glucagonoma patients there are no data available on their SSTR expression patterns (49). In 2006 we demonstrated, for the first time, a scattered immunopositivity for SSTRs in a case of malignant glucagonoma. We had access to polyclonal antibodies specifically targeted against SSTR5 and SSTR2 and we were therefore able to localize these two receptors in our histological sections. The immunopositivity was detected for both receptor subtypes in the membrane and in the cytoplasm of glucagonoma cells. We then treated our patient with a combination therapy consisting of the SST analog octreotide and interferon-a. The patient had a complete resolution of skin rash, normalization of plasma glucagon, chromogranin A, and neuron specific enolase levels and a metastatic disease stabilization. The patient's quality of life significantly improved, and she was alive 40 months after debulking surgery (50).

\section{THE EFFECTS OF HIGHER THAN USUAL DOSE OF SST ANALOGS}

It was suggested that higher than usual dose of SST analogs treatments $(>3.000 \mu \mathrm{g} /$ day) may promote the anti-proliferative effect, especially in those patients responding to standard doses $(2,17$, $18,83,94,95)$. A high-dose treatment with lanreotide (up to $12 \mathrm{mg}$ /day) produced tumor size reduction in 5\% and stabilization in $70 \%$ of the 19 patients. An induction of apoptosis in the tumors was observed in responding patients, a phenomenon not seen with regular doses of SST analogs, but often produced by chemotherapeutic agents (67). Subcutaneously injections of $5 \mathrm{mg}$ lanreotide three times a day for a period of 1 year produced one complete and one partial remission (PR) in 30 patients with functional midgut NETs; stable disease in 11 patients (36\%) and progression of the disease after 3-12 months of treatment in 11 patients (68). The treatment with high-dose SST analogs induced apoptosis in neuroendocrine tumors, while this was not found during treatment with low-dose SST, in a study where biopsy specimens were taken before and during SST analog treatment (66). In a highly select group of patients with progressive disease, $47 \%$ of the patients demonstrated at least stable disease when treated with a high dose of lanreotide (3-5 g/day) (82). High-dose formula of octreotide has been recently reported to stabilize hormone production and tumor growth in $75 \%$ of patients with advanced midgut carcinoid tumors and progressive disease with stabilization for 6-24 months (83). These effects may be attributable to SSTR 2, which is the most frequently expressed subtype and/or SSTR 5, 1, and 3 that are also expressed $(96,97)$. Data from a study with ultra-high-dose octreotide pamoate (Onco-LAR; Novartis) at $160 \mathrm{mg}$ intramuscularly every 2 weeks for 2 months followed by the same dose once monthly, appear to show some promise. Tumor size stabilization was obtained in 12 patients, a biochemical responses in 9 patients and/or stability in 11 . No significant tumor reduction was noted. At 6 months, the median plasma concentrations of octreotide were 25-100 times higher than those obtained by using octreotide-LAR at regular doses. A significant inhibition of angiogenesis was also showed through the down-regulation of proliferative factors such as VEGF and fibroblast growth factor (14). The highest response rates were reported using octreotide in doses $>30 \mathrm{mg}$ /day or lanreotide in doses $>5 \mathrm{mg} /$ day (and up to $15 \mathrm{mg} /$ day) (64). Tomassetti et al. have reported that after 1-year therapy, the tumor completely disappeared in three patients suffering from gastric carcinoid, two of whom were treated with lanreotide $30 \mathrm{mg}$ i.m. every 10 days (98). In a recent paper it was reported that in patients with Hashimoto's thyroiditis presenting ECL hyperplasia, considered a 
pre-neoplastic mark, the treatment with SST analog for 12 months resulted into the disappearance of ECL lesions (93). SST analogs can have a role in the treatment of digestive neuroendocrine tumors with low grades of malignancy, a low cellular proliferation index and high specific receptorial density in vivo as reported by Bombardieri et al. (29). In a very complete and well design paper of Ferolla et al. patients with well-differentiated neuroendocrine tumors, were treated with long-acting octreotide (LAR), conventionally administered at a dose of $30 \mathrm{mg}$ every 28 days; the end point of this study was to evaluate a different schedule of octreotide-LAR administration consistent with a shorter interval between administrations (21 days) in patients with a progressive disease at standard-dose interval. For this reason 28 patients who had tumor progression during therapy with LAR $30 \mathrm{mg}$ every 28 days were enrolled. Clinical, biological, and objective tumor response was evaluated after LAR $30 \mathrm{mg}$ every 21 days. Time to progression was also evaluated after LAR $30 \mathrm{mg}$ every 21 days and compared to LAR $30 \mathrm{mg}$ every 28 days. The treatment with LAR $30 \mathrm{mg}$ every 21 days resulted in complete and partial control of clinical symptoms in 40 and $60 \%$ of cases, respectively. Circulating neuroendocrine markers were significantly decreased in $30 \%$ of cases. A stabilization of disease was obtained in $93 \%$ and objective response in $7 \%$. The median time to progression was significantly longer by using the shortened interval of LAR administration as compared to the standard one (30 vs. 9 months, $p<0.0001)$ and the treatment was safe and well-tolerated. The authors conclude that the shortened schedule of LAR administration was able to re-institute control of clinical symptoms, to decrease level of circulating neuroendocrine markers and to increase time to progression in patients previously escaping from a standard schedule treatment (99).

\section{SOMATOSTATIN ANALOGS AND DIAGNOSTIC/THERAPEUTIC NUCLEAR MEDICINE}

Somatostatin receptors are able to form a receptor-ligand complex permitting the internalization and the accumulation of the radiopharmaceutical peptide inside the tumor using this procedures for diagnosis and radiometabolic treatments of these tumors (Figure 2). Peptide-receptor radionuclide therapy (PRRT) is an important treatment strategy for tumors that express adequate densities of SSTRs and has proven to be safe and effective. It was initially performed using indium-111 $(24,100)$. Recently, the development of SST peptides with higher receptor affinity conjugated with radio-metal labeling chelators, such as DOTA, which may be allow stable labeling with gallium, yttrium, or lutetium, changing the affinity profile for particular subtypes of SSTRs can permit new therapeutic options (101). Waldherr et al. evaluated the tumor response to targeted irradiation with the radiolabeled SST analog ${ }^{90}$ Y-DOTATOC in 41 patients with GEP-NET and bronchial tumors. They reported an ORR of $24 \%$. For endocrine pancreatic tumors it was $36 \%$. A complete remission was found in $2 \%$, a PR in $22 \%$, a minor response in $12 \%$, stable disease in $49 \%$, and progressive disease in $15 \%$ of patients. The treatment was welltolerated and there was a significant reduction of symptoms and the 2-year survival time was $76 \pm 16 \%$ (102). 177Lu DOTATATE [177Lu]DOTA-Tyr(3)-octreotate, a selective analog of SSTRs 2, in spite of its favorable affinity profile, at its maximum tolerated dose, it is limited by toxic effects on the kidney and bone marrow.
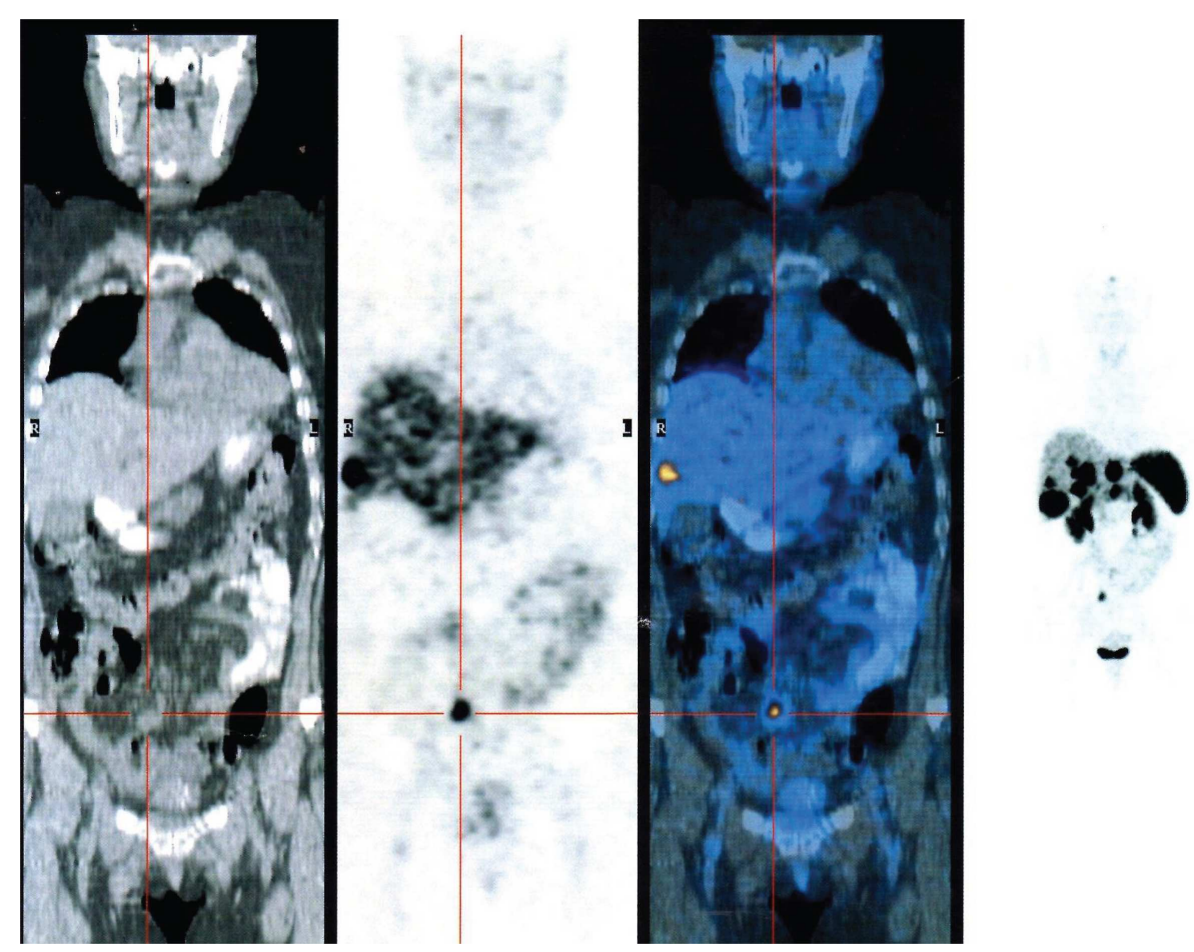

FIGURE 2 | PET gallium 68 DOTATOC showing the presence of multiple liver metastasis from neuroendocrine ileal tumor. 
Nevertheless, the results seem encouraging compared with historical therapeutic data (103). Kwekkeboom et al. obtained promising results using 177Lu DOTATATE [177Lu]DOTA-Tyr(3)-octreotate in 131 patients with NETs. A complete remission was observed in $2 \%$ of patients, a PR in $26 \%$, a minor response in $19 \%$, stable disease in $35 \%$, and progressive disease in $18 \%$ of patients. Higher remission rates were positively correlated with high uptake on pre-therapy SSTRs imaging, whereas progressive disease was significantly more frequent in patients with extensive disease. Median time to progression was more than 36 months (24). The combination of ${ }^{90} \mathrm{Y}$ - and ${ }^{177} \mathrm{Lu}$-labeled analogs (104) seems to have had superior antitumor effects when compared with either ${ }^{90} \mathrm{Y}$ - or ${ }^{177} \mathrm{Lu}$-analog in animals presenting with tumors of various sizes. It has been reported that ${ }^{177}$ Lutetium may be more effective for smaller tumors whereas ${ }^{90} \mathrm{Yttrium}$ may be more effective for larger tumors $(105,106)$.

\section{SOMATOSTATIN ANALOGS AND INTERFERON}

The combination of SSAs and interferon (IFN) has been used in an effort to enhance the anti-proliferative effect of IFN therapy, to add the positive effect of SSAs on hypersecretory syndromes, and to reduce the dose of IFN and thus the number of IFN-related sideeffects. Whether SST analogs and IFN show a synergistic effect on tumor growth and in carcinoid syndrome symptom management is matter of debate. The combination therapy with SST analogs and IFN is in fact limited by the small number of trials, with variable results. This combination seems of benefit in patients where the usual octreotide treatment failed to achieve a biochemical and symptomatic control (107).

\section{CONCLUSION}

Neuroendocrine tumors of the gastroenteropancreatic (GEPNETs) system comprise a rare group of malignant neoplasms. The SST analogs have been shown to be very useful for symptomatic and biochemical improvement in patients with these tumors while preclinical and clinical studies provide conflicting results on their antitumor effects. The mechanisms of these effects are unknown, but probably are in part due to direct effects on proliferative signaling pathways, activation of apoptosis, and effects on angiogenesis. Biological response to SST analogs depends on distribution and level of expression of SSTRs subtypes in tumors, and the expression of selective SSTR-signaling pathway molecules. The high density of SSTR 2 in endocrine tumors explains the use of SSTR 2 specific analogs in the diagnosis and treatment of these tumors. However, the role of SSTR 1, 3, and 5 appears to be of increasing interest. The development of new peptidic and non-peptidic SST analogs, subtype selective agonists, chimeric analogs, or pan-SST analogs will probably improve the diagnosis and treatment of GEPNETs, which express SSTRs other than SSTR 2. The combination of SSAs and IFN seems of benefit in patients where the treatment with SST analogs alone failed to achieve a biochemical and symptomatic control while their synergistic effect on tumor growth is still unknown. The analysis of the SSTR status specifically for each patient, and studies of individual tumor biological behavior, might be of therapeutic interest and could help to optimize treatment especially in unresectable tumors. Peptide-receptor-targeted radiotherapy for advanced disease using radiolabeled octapeptide analogs appears to be a significant progress in the treatment of GEP-NETs but data are limited, mainly about the best time for its administration, or what is the most appropriate radioligand/combination to be used for each patient, and if and how the doses should be fractionated. Novel strategies based on SSTR 2 receptor gene transfer to target tumor growth and angiogenesis might offer new prospectives of therapeutic interest mainly to treat unresectable tumors. Prospective studies including large number of patients regarding the optimal dosage and modes of administration of SST analogs and the development of new slow release, SSTR subtype specific compounds are needed.

\section{REFERENCES}

1. Ramage JK, Davies AH, Ardill J, Bax N, Caplin M, Grossman A, et al. Guidelines for the management of gastroenteropancreatic neuroendocrine (including carcinoid) tumours. Gut (2005) 54(Suppl 4):iv1-16. doi:10.1136/gut.2004.053314

2. Modlin IM, Oberg K, Chung DC, Jensen RT, de Herder WW, Thakker RV, et al. Gastroenteropancreatic neuroendocrine tumours. Lancet Oncol (2008) 9(1):61-72. doi:10.1016/S1470-2045(07)70410-2

3. Pearse AG. The cytochemistry and ultrastructure of polypeptide hormoneproducing cells of the APUD series and the embryologic, physiologic and pathologic implications of the concept. J Histochem Cytochem (1969) 17:303-13. doi:10.1177/17.5.303

4. Solcia E, Kloppel G, Sobin LH. Histological Typing of Endocrine Tumours. World Health Organization International Histological Classification of Tumours, Second Edition. Heidelberg: Springer (2000).

5. Pape UF, Jann H, Muller-Nordhorn J, Bockelbrink A, Berndt U, Willich SN, et al. Prognostic relevance of a novel TNM classification system for upper gastroenteropancreatic neuroendocrine tumors. Cancer (2008) 113(2):256-65. doi:10.1002/cncr.23549

6. Plockinger U, Rindi G, Arnold R, Eriksson B, Krenning EP, de Herder WW, et al. Guidelines for the diagnosis and treatment of neuroendocrine gastrointestinal tumours. A consensus statement on behalf of the European Neuroendocrine Tumour Society (ENETS). Neuroendocrinology (2004) 80(6):394-424. doi:10.1159/000085237

7. Beneyto M, Morris HM, Rovensky KC, Lewis DA. Lamina- and cell-specific alterations in cortical somatostatin receptor $2 \mathrm{mRNA}$ expression in schizophrenia. Neuropharmacology (2012) 62(3):1598-605. doi:10.1016/j.neuropharm. 2010.12.029

8. Pasquali D, Notaro A, Bonavolonta' G, Vassallo P, Bellastella A, Sinisi AA. Somatostatin receptor genes are expressed in lymphocytes from retroorbital tissues in Graves' disease. J Clin Endocrinol Metab (2002) 87(11):5125-9. doi:10.1210/jc.2002-020790

9. Reubi JC, Laissue J, Krenning E, Lamberts SW. Somatostatin receptors in human cancer: incidence, characteristics, functional correlates and clinical implications. J Steroid Biochem Mol Biol (1992) 43(1-3):27-35. doi:10.1016/ 0960-0760(92)90184-K

10. Buscail L, Saint-Laurent N, Chastre E, Vaillant JC, Gespach C, Capella G, et al. Loss of sst2 somatostatin receptor gene expression in human pancreatic and colorectal cancer. Cancer Res (1996) 56(8):1823-7.

11. Ferone D, Gatto F, Arvigo M, Resmini E, Boschetti M, Teti C, et al. The clinicalmolecular interface of somatostatin, dopamine and their receptors in pituitary pathophysiology. J Mol Endocrinol (2009) 42(5):361-70. doi:10.1677/JME-080162

12. Papotti M, Bongiovanni M, Volante M, Allia E, Landolfi S, Helboe L, et al. Expression of somatostatin receptor types 1-5 in 81 cases of gastrointestinal and pancreatic endocrine tumors. A correlative immunohistochemical and reverse-transcriptase polymerase chain reaction analysis. Virchows Arch (2002) 440:461-75. doi:10.1007/s00428-002-0609-x

13. Janson ET, Oberg K. Neuroendocrine tumors-somatostatin receptor expression and somatostatin analog treatment. Cancer Chemother Biol Response Modif (2003) 21:535-46. doi:10.1016/S0921-4410(03)21025-5

14. Oberg K. Future aspects of somatostatin-receptor-mediated therapy. Neuroendocrinology (2004) 80:57-61. doi:10.1159/000080743

15. Oberg K, Kvols L, Caplin M. Consensus report on the use of somatostatin analogs for the management of neuroendocrine tumors of the 
gastroenteropancreatic system. Ann Oncol (2004) 15(6):966-73. doi:10.1093/ annonc/mdh216

16. Antonijoan RM, Barbanoj MJ, Cordero JA, Peraire C, Obach R, Valles J, et al. Pharmacokinetics of a new Autogel formulation of the somatostatin analogue lanreotide after a single subcutaneous dose in healthy volunteers. J Pharm Pharmacol (2004) 56(4):471-6. doi:10.1211/0022357023123

17. Bruns C, Lewis I, Briner U, Meno-Tetang G, Weckbecker G. SOM230: a novel somatostatin peptidomimetic with broad somatotropin release inhibiting factor (SRIF) receptor binding and a unique antisecretory profile. Eur J Endocrinol (2002) 146(5):707-16. doi:10.1530/eje.0.1460707

18. Pasquali D, Rossi V, Conzo G, Pannone G, Bufo P, De Bellis A, et al. Effects of somatostatin analog SOM230 on cell proliferation, apoptosis, and catecholamine levels in cultured pheochromocytoma cells. J Mol Endocrinol (2008) 40(6):263-71. doi:10.1677/JME-08-0012

19. Plockinger U. Biotherapy. Best Pract Res Clin Endocrinol Metab (2007) 21:145-62. doi:10.1016/j.beem.2007.01.002

20. Grozinsky-Glasberg S, Shimon I, Korbonits M, Grossman AB. Somatostatin analogues in the control of neuroendocrine tumours: efficacy and mechanisms. Endocr Relat Cancer (2008) 15(3):701-20. doi:10.1677/ERC-07-0288

21. de Herder WW, Kwekkeboom DJ, Feelders RA, van Aken MO, Lamberts SW, van der Lely AJ, et al. Somatostatin receptor imaging for neuroendocrine tumors. Pituitary (2006) 9(3):243-8. doi:10.1007/s11102-006-0270-5

22. Janson ET, Kalkner KM, Eriksson B, Westlin JE, Oberg K. Somatostatin receptor scintigraphy during treatment with lanreotide in patients with neuroendocrine tumors. Nucl Med Biol (1999) 26(8):877-82. doi:10.1016/S0969-8051(99) 00059- 1

23. Krenning EP, de Jong M, Kooij PP, Breeman WA, Bakker WH, de Herder WW, et al. Radiolabelled somatostatin analogue(s) for peptide receptor scintigraphy and radionuclide therapy. Ann Oncol (1999) 10(Suppl 2):S23-9. doi:10.1023/ A:1027396313397

24. Kwekkeboom DJ, Teunissen JJ, Bakker WH, Kooij PP, de Herder WW, Feelders RA, et al. Radiolabeled somatostatin analog (177Lu-DOTA0, Tyr3)octreotate in patients with endocrine gastroenteropancreatic tumors. J Clin Oncol (2005) 23(12):2754-62. doi:10.1200/JCO.2005.08.066

25. Lamberts SW, Bakker WH, Reubi JC, Krenning EP. Treatment with Sandostatin and in vivo localization of tumors with radiolabeled somatostatin analogs. Metabolism (1990) 39(9 Suppl 2):152-5. doi:10.1016/0026-0495(90) 90235-5

26. Lamberts SW, de Herder WW, Hofland LJ. Somatostatin analogs in the diagnosis and treatment of cancer. Trends Endocrinol Metab (2002) 13:451-7. doi:10.1016/S1043-2760(02)00667-7

27. van Eyck CH, Bruining HA, Reubi JC, Bakker WH, Oei HY, Krenning EP, et al. Use of isotope-labeled somatostatin analogs for visualization of islet cell tumors. World J Surg (1993) 17(4):444-7. doi:10.1007/BF01655102

28. Dogliotti L, Tampellini M, Stivanello M, Gorzegno G, Fabiani L. The clinical management of neuroendocrine tumors with long-acting repeatable (LAR) octreotide: comparison with standard subcutaneous octreotide therapy. Ann Oncol (2001) 12:S105-9. doi:10.1023/A:1012465215904

29. Bombardieri E, Seregni E, Savelli G, Villano C, Castellani MR, Cirillo F, et al. Radiolabeled somatostaitin analogs in the treatment of neuroendocrine tumors: experience of the National Cancer Institute of Milano using high dose of $111 \mathrm{In}$-pentetreotide in metastatic neuroendocrine gastroenteropancreatic tumors. J Endocrinol Invest (2003) 26(Suppl 8):63-69.

30. Moertel CG. Karnofsky memorial lecture. An odyssey in the land of small tumors. J Clin Oncol (1987) 5:1502-22.

31. di Bartolomeo M, Bajetta E, Buzzoni R, Mariani L, Carnaghi C, Somma L, et al. Clinical efficacy of octreotide in the treatment of metastatic neuroendocrine tumors. A study by the Italian Trials in Medical Oncology Group. Cancer (1996) 77(2):402-8. doi:10.1002/(SICI) 1097-0142(19960115)77:2<402::AIDCNCR25>3.0.CO;2-4

32. Delaunoit T, Neczyporenko F, Rubin J, Erlichman C, Hobday TJ. Medical management of pancreatic neuroendocrine tumors. Am J Gastroenterol (2008) 103(2):475-83. doi:10.1111/j.1572-0241.2007.01643.x

33. Bauer W, Briner U, Doepfner W, Haller R, Huguenin R, Marbach P, et al. SMS 201-995: a very potent and selective octapeptide analogue of somatostatin with prolonged action. Life Sci (1982) 31(11):1133-40. doi:10.1016/0024-3205(82) 90087-X
34. Rubin J, Ajani J, Schirmer W, Venook AP, Bukowski R, Pommier R, et al. Octreotide acetate long-acting formulation versus open-label subcutaneous octreotide acetate in malignant carcinoid syndrome. J Clin Oncol (1999) 17(2):600-6.

35. O’Toole D, Ducreux M, Bommelaer G, Wemeau JL, Bouche O, Catus F, et al. Treatment of carcinoid syndrome: a prospective crossover evaluation of lanreotide versus octreotide in terms of efficacy, patient acceptability, and tolerance. Cancer (2000) 88(4):770-6. doi:10.1002/(SICI)1097-0142(20000215)88: $4<770:$ :AID-CNCR6>3.0.CO;2-0

36. Ruszniewski P, Ish-Shalom S, Wymenga M, O’Toole D, Arnold R, Tomassetti $\mathrm{P}$, et al. Rapid and sustained relief from the symptoms of carcinoid syndrome: results from an open 6-month study of the 28-day prolonged release formulation of lanreotide. Neuroendocrinology (2004) 80(4):244-51. doi: $10.1159 / 000082875$

37. Kvols LK, Oberg KE, O’Dorisio TM, Mohideen P, de Herder WW, Arnold R, et al. Pasireotide (SOM230) shows efficacy and tolerability in the treatment of patients with advanced neuroendocrine tumors refractory or resistant to octreotide LAR: results from a phase II study. Endocr Relat Cancer (2012) 19(5):657-66. doi:10.1530/ERC-11-0367

38. Kulke MH, Mayer RJ. Carcinoid tumors. N Engl J Med (1999) 340:858-68. doi:10.1056/NEJM199903183401107

39. Reubi JC. Somatostatin and other peptide receptors as tools for tumor diagnosis and treatment. Neuroendocrinology (2004) 80:51-6. doi:10.1159/ 000080742

40. Vezzosi D, Bennet A, Rochaix P, Courbon F, Selves J, Pradere B, et al. Octreotide in insulinoma patients: efficacy on hypoglycemia, relationships with octreoscan scintigraphy and immunostaining with anti-sst $2 \mathrm{~A}$ and anti-sst 5 antibodies. Eur J Endocrinol (2005) 152:757-67. doi:10.1530/eje.1.01901

41. Hearn PR, Ahmed M, Woodhouse NJ. The use of SMS 201-995 (somatostatin analogue) in insulinomas. Additional case report and literature review. Horm Res (1998) 29:211-3.

42. Hearn PR, Reynolds CL, Johansen K, Woodhouse NJ. Lung carcinoid with Cushing's syndrome: control of serum ACTH and cortisol levels using SMS 201-995 (sandostatin). Clin Endocrinol (Oxf) (1988) 28:181-5.

43. Tanaka Y, Funahashi H, Imai T, Naruse T, Suzumura K, Oda Y. The effectiveness of administering a minimal dose of octreotide long-term prior to surgery for insulinoma: report of a case. Surg Today (2000) 30:541-3. doi:10.1007/s005950070124

44. Verschoor L, Uitterlinden P, Lamberts SW, Del Pozo E. On the use of a new somatostatin analogue in the treatment of hypoglycaemia in patients with insulinoma. Clin Endocrinol (Oxf) (1986) 25:555-60. doi:10.1111/j.1365-2265. 1986.tb03609.x

45. von Eyben FE, Grodum E, Gjessing HJ, Hagen C, Nielsen H. Metabolic remission with octreotide in patients with insulinoma. J Intern Med (1994) 235:245-8. doi:10.1111/j.1365-2796.1994.tb01067.x

46. Casadei R, Tomassetti P, Rossi C, la Donna M, Migliori M, Marrano D. Treatment of metastatic glucagonoma to the liver: case report and literature review. Ital J Gastroenterol Hepatol (1999) 31:308-12.

47. Tomassetti P, Migliori M, Corinaldesi R, Gullo L. Treatment of gastroenteropancreatic neuroendocrine tumours with octreotide LAR. Aliment Pharmacol Ther (2000) 14:557-60. doi:10.1046/j.1365-2036.2000.00738.x

48. Wermers RA, Fatourechi V, Wynne AG, Kvols LK, Lloyd RV. The glucagonoma syndrome. Clinical and pathologic features in 21 patients. Medicine (Baltimore) (1996) 75:53-63. doi:10.1097/00005792-199603000-00002

49. Grozinsky-Glasberg S, Grossman AB, Korbonits M. The role of somatostatin analogues in the treatment of neuroendocrine tumours. Mol Cell Endocrinol (2008) 286:238-50. doi:10.1016/j.mce.2007.10.006

50. Appetecchia M, Ferretti E, Carducci M, Izzo F, Carpanese L, Marandino F, et al. Malignant glucagonoma. New options of treatment. J Exp Clin Cancer Res (2006) 25(1):135-9.

51. Soga J, Yakuwa Y. Somatostatinoma/inhibitory syndrome: a statistical evaluation of 173 reported cases as compared to other pancreatic endocrinomas. J Exp Clin Cancer Res (1999) 18:13-22.

52. Angeletti S, Corleto VD, Schillaci O, Marignani M, Annibale B, Moretti A, et al. Use of the somatostatin analogue octreotide to localise and manage somatostatin-producing tumours. Gut (1998) 42:792-4. doi:10.1136/gut.42. 6.792 
53. Ghaferi AA, Chojnacki KA, Long WD, Cameron JL, Yeo CJ. Pancreatic VIPomas: subject review and one institutional experience. J Gastrointest Surg (2007) 12:382-93. doi:10.1007/s11605-007-0177-0

54. Song S, Shi R, Li B, Liu Y. Diagnosis and treatment of pancreatic vasoactive intestinal peptide endocrine tumors. Pancreas (2009) 38(7):811-4. doi:10. 1097/MPA.0b013e3181b2bc7c

55. Nakayama S, Yokote T, Kobayashi K, Hirata Y, Hiraiwa T, Komoto I, et al. VIPoma with expression of both VIP and VPAC1 receptors in a patient with WDHA syndrome. Endocrine (2009) 35:143-6. doi:10.1007/s12020-0099146-6

56. Schally AV. Oncological applications of somatostatin analogues. Cancer Res (1988) 48:6977-85.

57. Pollak MN, Schally AV. Mechanisms of antineoplastic action of somatostatin analogs. Proc Soc Exp Biol Med (1998) 217:143-52. doi:10.3181/00379727-21744216

58. Weckbecker G, Raulf F, Stolz B, Bruns C. Somatostatin analogs for diagnosis and treatment of cancer. Pharmacol Ther (1993) 60:245-64.

59. Froidevaux S, Eberle AN. Somatostatin analogs and radiopeptides in cancer therapy. Biopolymers (2002) 66:161-83. doi:10.1002/bip.10256

60. Schally AV, Nagy A. Chemotherapy targeted to cancers through tumoral hormone receptors. Trends Endocrinol Metab (2004) 15:300-10. doi:10.1016/j.tem. 2004.07.002

61. Pyronnet S, Bousquet C, Najib S, Azar R, Laklai H, Susini C. Antitumor effects of somatostatin. Mol Cell Endocrinol (2008) 286:230-7. doi:10.1016/j.mce.2008. 02.002

62. Jensen RT. Carcinoid and pancreatic endocrine tumors: recent advances in molecular pathogenesis, localization, and treatment. Curr Opin Oncol (2000) 12:368-77. doi:10.1097/00001622-200007000-00015

63. Reubi JC. A somatostatin analogue inhibits chondrosarcoma and insulinoma tumour growth. Acta Endocrinol (Copenh) (1985) 109:108-14.

64. Sinisi AA, Bellastella A, Prezioso D, Nicchio MR, Lotti T, Salvatore M, et al. Different expression patterns of somatostatin receptor subtypes in cultured epithelial cells from human normal prostate and prostate cancer. J Clin Endocrinol Metab (1997) 82(8):2566-9. doi:10.1210/jc.82.8.2566

65. Scarpignato C, Pelosini I. Somatostatin analogs for cancer treatment and diagnosis: an overview. Chemotherapy (2001) 47:1-29. doi:10.1159/ 000049157

66. Imam H, Eriksson B, Lukinius A, Janson ET, Lindgren PG, Wilander E, et al. Induction of apoptosis in neuroendocrine tumors of the digestive system during treatment with somatostatin analogs. Acta Oncol (1997) 36:607-14. doi:10.3109/02841869709001323

67. Eriksson B, Renstrup J, Imam H, Oberg K. High-dose treatment with lanreotide of patients with advanced neuroendocrine gastrointestinal tumors: clinical and biological effects. Ann Oncol (1997) 8:1041-4. doi:10.1023/A: 1008205415035

68. Faiss S, Rath U, Mansmann U, Caird D, Clemens N, Riecken EO, et al. Ultra-high-dose lanreotide treatment in patients with metastatic neuroendocrine gastroenteropancreatic tumors. Digestion (1999) 60:469-76. doi:10. $1159 / 000007693$

69. Lawnicka H, Stepien H, Wyczołkowska J, Kolago B, Kunert-Radek J, Komorowski J. Effect of somatostatin and octreotide on proliferation and vascular endothelial growth factor secretion from murine endothelial cell line (HECa10) culture. Biochem Biophys Res Commun (2000) 268:567-71. doi:10.1006/bbrc.2000.2119

70. Treiber G, Wex T, Rocken C, Fostitsch P, Malfertheiner P. Impact of biomarkers on disease survival and progression in patients treated with octreotide for advanced hepatocellular carcinoma. J Cancer Res Clin Oncol (2006) 132:699-708. doi:10.1007/s00432-006-0118-4

71. Dimitroulopoulos D, Xinopoulos D, Tsamakidis K, Zisimopoulos A, Andriotis E, Panagiotakos D, et al. Long acting octreotide in the treatment of advanced hepatocellular cancer and overexpression of somatostatin receptors: randomized placebo-controlled trial. World J Gastroenterol (2007) 13: 3164-70.

72. Lamberts SW, Krenning EP, Reubi JC. The role of somatostatin and its analogs in the diagnosis and treatment of tumors. Endocr Rev (1991) 12:450-82. doi:10.1210/edrv-12-4-450

73. Bousquet C, Puente E, Buscail L, Vaysse N, Susini C. Antiproliferative effect of somatostatin and analogs. Chemotherapy (2001) 47:30-9. doi:10.1159/ 000049159
74. Danesi R, Agen C, Benelli U, Paolo AD, Nardini D, Bocci G, et al. Inhibition of experimental angiogenesis by the somatostatin analogue octreotide acetate (SMS 201-995). Clin Cancer Res (1997) 3:265-72.

75. Woltering EA, Watson JC, Alperin-Lea RC, Sharma C, Keenan E, Kurozawa D, et al. Somatostatin analogs: angiogenesis inhibitors with novel mechanisms of action. Invest New Drugs (1997) 15:77-86. doi:10.1023/A:1005774713202

76. Anthony L, Johnson D, Hande K, Shaff M, Winn S, Krozely M, et al. Somatostatin analogue phase I trials in neuroendocrine neoplasms. Acta Oncol (1993) 32:217-23. doi:10.3109/02841869309083915

77. Kvols LK, Woltering EA. Role of somatostatin analogs in the clinical management of non-neuroendocrine solid tumors. Anticancer Drugs (2006) 17:601-8. doi:10.1097/01.cad.0000210335.95828.ed

78. Arnold R, Benning R, Neuhaus C, Rolwage M, Trautmann ME. Gastroenteropancreatic endocrine tumours: effect of Sandostatin on tumour growth. The German Sandostatin Study Group. Digestion (1993) 54:72-5. doi:10.1159/ 000201081

79. Arnold R, Trautmann ME, Creutzfeldt W, Benning R, Benning M, Neuhaus C, et al. Somatostatin analogue octreotide and inhibition of tumour growth in metastatic endocrine gastroenteropancreatic tumours. Gut (1996) 38:430-8. doi:10.1136/gut.38.3.430

80. Saltz L, Trochanowski B, Buckley M, Heffernan B, Niedzwiecki D, Tao Y, et al. Octreotide as an antineoplastic agent in the treatment of functional and nonfunctional neuroendocrine tumors. Cancer (1993) 72:244-8. doi:10.1002/ 1097-0142(19930701)72:1<244::AID-CNCR2820720143>3.0.CO;2-Q

81. Panzuto F, Di Fonzo M, Iannicelli E, Sciuto R, Maini CL, Capurso G, et al. Longterm clinical outcome of somatostatin analogues for treatment of progressive, metastatic, well-differentiated entero-pancreatic endocrine carcinoma. Ann Oncol (2006) 17:461-6. doi:10.1093/annonc/mdj113

82. Faiss S, Scherubl H, Riecken EO, Wiedenmann B. Drug therapy in metastatic neuroendocrine tumors of the gastroenteropancreatic system. Recent Results Cancer Res (1996) 142:193-207. doi:10.1007/978-3-642-80035-1_12

83. Welin SV, Janson ET, Sundin A, Stridsberg M, Lavenius E, Granberg D, et al. High-dose treatment with a long-acting somatostatin analogue in patients with advanced midgut carcinoid tumours. Eur J Endocrinol (2004) 151:107-12. doi:10.1530/eje.0.1510107

84. Arnold R, Rinke A, Klose KJ, Muller HH, Wied M, Zamzow K, et al. Octreotide versus octreotide plus interferon-alpha in endocrine gastroenteropancreatic tumors: a randomized trial. Clin Gastroenterol Hepatol (2005) 3:761-71. doi:10.1016/S1542-3565(05)00481-7

85. Rinke A, Muller HH, Schade-Brittinger C, Klose KJ, Barth P, Wied M, et al. Placebo-controlled, double-blind, prospective, randomized study on the effect of octreotide LAR in the control of tumor growth in patients with metastatic neuroendocrine midgut tumors: a report from the PROMID Study Group. J Clin Oncol (2009) 27:4656-63. doi:10.1200/JCO.2009.22.8510

86. Shojamanesh H, Gibril F, Louie A, Ojeaburu JV, Bashir S, Abou-Saif A, et al. Prospective study of the antitumor efficacy of long-term octreotide treatment in patients with progressive metastatic gastrinoma. Cancer (2002) 94:331-43. doi:10.1002/cncr.10195

87. Prommegger R, Bale R, Ensinger C, Sauper T, Profanter C, Knoflach M, et al. Gastric carcinoid type I tumour: new diagnostic and therapeutic method. Eur J Gastroenterol Hepatol (2003) 15:705-7. doi:10.1097/00042737-20030600000020

88. Fykse V, Sandvik AK, Qvigstad G, Falkmer SE, Syversen U, Waldum HL. Treatment of ECL cell carcinoids with octreotide LAR. Scand J Gastroenterol (2004) 39:621-8. doi:10.1080/00365520410005225

89. Dworakowska D, Wlodek E, Leontiou C, Igreja S, Cakir M, Teng M, et al. Activation of Raf/MEK/ERK and PI3K/Akt/mTOR pathways in pituitary adenomas and their effects on downstream effectors. Endocr Relat Cancer (2009) 16(4):1329-38. doi:10.1677/ERC-09-0101

90. Romeo S, Milione M, Gatti A, Fallarino M, Corleto V, Morano S, et al. Complete clinical remission and disappearance of liver metastases after treatment with somatostatin analogue in a 40-year-old woman with a malignant insulinoma positive for somatostatin receptors type 2. Horm Res (2006) 65:120-5. doi:10.1159/000091408

91. Bondanelli M, Ambrosio MR, Zatelli MC, Cavazzini L, Al Jandali Rifa’y L, degli Uberti EC. Regression of liver metastases of occult carcinoid tumor with slow release lanreotide therapy. World J Gastroenterol (2005) 11:2041-4.

92. Klijn JG, Hoff AM, Planting AS, Verweij J, Kok T, Lamberts SW, et al. Treatment of patients with metastatic pancreatic and gastrointestinal tumours with 
the somatostatin analogue Sandostatin: a phase II study including endocrine effects. Br J Cancer (1990) 62:627-30. doi:10.1038/bjc.1990.343

93. Renzullo A, Accardo G, Esposito D, De Bellis A, Bizzarro A, Romano M, et al. Hashimoto's thyroiditis and ECL hyperplasia: early detection and SST analog treatment. Eur J Inflamm (2013). (in press).

94. Ducreux M, Ruszniewski P, Chayvialle JA, Blumberg J, Cloarec D, Michel $\mathrm{H}$, et al. The antitumoral effect of the long-acting somatostatin analog lanreotide in neuroendocrine tumors. Am J Gastroenterol (2000) 95:3276-81. doi:10.1111/j.1572-0241.2000.03210.x

95. Aparicio T, Ducreux M, Baudin E, Sabourin JC, De Baere T, Mitry E, et al. Antitumour activity of somatostatin analogues in progressive metastatic neuroendocrine tumours. Eur J Cancer (2001) 37:1014-9. doi:10.1016/S0959-8049(01) 00073-9

96. Reubi JC, Waser B. Concomitant expression of several peptide receptors in neuroendocrine tumours: molecular basis for in vivo multireceptor tumour targeting. Eur J Nucl Med Mol Imaging (2003) 30:781-93. doi:10.1007/s00259003-1184-3

97. O’Toole D, Saveanu A, Couvelard A, Gunz G, Enjalbert A, Jaquet P, et al. The analysis of quantitative expression of somatostatin and dopamine receptors in gastro-entero-pancreatic tumours opens new therapeutic strategies. Eur J Endocrinol (2006) 155:849-57. doi:10.1530/eje.1.02307

98. Tomassetti P, Migliori M, Caletti GC, Fusaroli P, Corinaldesi R, Gullo L. Treatment of type II gastric carcinoid tumors with somatostatin analogues. $N$ Engl J Med (2000) 343:551-4. doi:10.1056/NEJM200008243430805

99. Ferolla P, Faggiano A, Grimaldi F, Ferone D, Scarpelli G, Ramundo V, et al. Shortened interval of long-acting octreotide administration is effective in patients with well-differentiated neuroendocrine carcinomas in progression on standard doses. J Endocrinol Invest (2012) 35(3):326-31. doi:10.3275/7869

100. Fjälling M, Andersson P, Forssell-Aronsson E, Grétarsdóttir J, Johansson V, Tisell LE, et al. Systemic radionuclide therapy using indium-111-DTPA-DPhel-octreotide in midgut carcinoid syndrome. J Nucl Med (1996) 37:1519-21.

101. Heppeler A, Froidevaux S, Eberle AN, Maecke HR. Receptor targeting for tumor localisation and therapy with radiopeptides. Curr Med Chem (2000) 7:971-94. doi:10.2174/0929867003374516

102. Forrer F, Valkema R, Kwekkeboom DJ, de Jong M, Krenning EP. Neuroendocrine tumors. Peptide receptor radionuclide therapy. Best Pract Res Clin Endocrinol Metab (2007) 21:111-29. doi:10.1016/j.beem.2007.01.007
103. de Jong M, Valkema R, Jamar F, Kvols LK, Kwekkeboom DJ, Breeman WA, et al. Somatostatin receptor-targeted radionuclide therapy of tumors: preclinical and clinical findings. Semin Nucl Med (2002) 32(2):133-40. doi:10.1053/ snuc. 2002.31027

104. de Jong M, Breeman WA, Valkema R, Bernard BF, Krenning EP. Combination radionuclide therapy using $177 \mathrm{Lu}-$ and $90 \mathrm{Y}$-labeled somatostatin analogs. $J$ Nucl Med (2005) 46(Suppl 1):13S-7S.

105. Oberg K, Eriksson B. Nuclear medicine in the detection, staging and treatment of gastrointestinal carcinoid tumours. Best Pract Res Clin Endocrinol Metab (2005) 19:265-76. doi:10.1016/j.beem.2004.11.016

106. Chan JA, Kulke MK. Emerging therapies for the treatment of patients with advanced neuroendocrine tumors. Expert Opin Emerg Drugs (2007) 12:253-70. doi:10.1517/14728214.12.2.253

107. Tiensuu Janson EM, Ahlström H, Andersson T, Oberg KE. Octreotide and interferon alfa: a new combination for the treatment of malignant carcinoid tumours. Eur J Cancer (1992) 28:1647-50. doi:10.1016/0959-8049(92)90060-F

Conflict of Interest Statement: The authors declare that the research was conducted in the absence of any commercial or financial relationships that could be construed as a potential conflict of interest.

Received: 06 September 2013; paper pending published: 08 October 2013; accepted: 13 January 2014; published online: 07 February 2014.

Citation: Baldelli R, Barnabei A, Rizza L, Isidori AM, Rota F, Di Giacinto P, Paoloni A, Torino F, Corsello SM, Lenzi A and Appetecchia M (2014) Somatostatin analogs therapy in gastroenteropancreatic neuroendocrine tumors: current aspects and new perspectives. Front. Endocrinol. 5:7. doi: 10.3389/fendo.2014.00007

This article was submitted to Cancer Endocrinology, a section of the journal Frontiers in Endocrinology.

Copyright (C) 2014 Baldelli, Barnabei, Rizza, Isidori, Rota, Di Giacinto, Paoloni, Torino, Corsello, Lenzi and Appetecchia. This is an open-access article distributed under the terms of the Creative Commons Attribution License (CC BY). The use, distribution or reproduction in other forums is permitted, provided the original author(s) or licensor are credited and that the original publication in this journal is cited, in accordance with accepted academic practice. No use, distribution or reproduction is permitted which does not comply with these terms. 